\title{
TECNOLOGIA DIGITAL NO ENSINO DE LÍNGUA INGLESA: O KAHOOT! COMO AVALIAÇÃO FORMATIVA
}

\author{
Igor Tairone Ramos dos Santos* \\ Denise Aparecida Brito Barreto**
}

Cláudia Vivien Carvalho de Oliveira Soares***

RESUMO: O presente trabalho é fruto de um recorte de pesquisa advindo de uma dissertação de mestrado, cuja pesquisa foi realizada numa turma de quarto ano do Ensino Médio, do curso de Informática na Modalidade Integrada do Instituto Federal da Bahia, campus Vitória da Conquista. O objetivo geral deste artigo foiinvestigar como a Avaliação Formativa, mediada por Tecnologias Digitais, pode potencializar o processo de ensino-aprendizagem de Língua Inglesa. Embora vários aspectos tenham sido abordados na referida dissertação, enfocamos na tecnologia digital e na sua potencialidade para a realização de ensino-aprendizagem de língua inglesa de forma lúdica e eficiente. Com base em autores como Lucena (2004), Brun (2003) e Levy (1999), realizamos uma pesquisa qualitativa de cunho exploratório, cuja coleta de dados se concentrou na coleta de resultados através da aplicação do jogo digital Kahoot! (produção final de uma sequência didática). Percebemos que a tecnologia digital tem a capacidade de contribuir para um ensino de Língua Inglesa de forma dinâmica, além de promover um ambiente lúdico na sala de aula, o que desperta interesse dos alunos em tais atividades, visto que a sociedade está em constante evolução no mundo cada vez mais digital.

PALAVRAS-CHAVE: Ensino de Língua Inglesa; Tecnologia Digital; Avaliação Formativa.

\section{Introdução}

O ensino de idiomas no Brasil é preconizado pelos Parâmetros Curriculares Nacionais para o Ensino Médio - PCNEM, publicados em 2000, cujos pressupostos ressaltam a importância e o caráter obrigatório do ensino de Língua Inglesa nas escolas (BRASIL, 1998). Porém, no Brasil, existem vários desafios para que o ensino de Língua Inglesa ocorra de forma efetiva. Dentre eles podemos citar a dificuldade estrutural das instituições

\footnotetext{
* Mestrando em Educação pela Universidade Estadual do Sudoeste da Bahia (Uesb).

** Doutora em Educação pela Universidade Federal da Bahia (Ufba). Realizou estágio de pós-doutorado em Educação na Faculdade de Psicologia e Ciências da Educação em Coimbra. Professora plena da Universidade Estadual do Sudoeste da Bahia (Uesb). Integrante do Grupo de Pesquisa Linguagem e Educação (GPLEd) cadastrado no CNPQ.

*** Doutora em Letras pela Universidade Federal da Bahia (Ufba). Professora Titular da Universidade Estadual do Sudoeste da Bahia (Uesb).
} 
educacionais, em grande parte públicas, na aquisição de equipamentos, deixando as aulas dependentes apenas de materiais didáticos escritos e muitas vezes maçantes, até a falta de fluência por parte dos docentes, o que cria um ambiente de desinteresse e dificuldade de aprendizado de idiomas.

Para o aprendizado de uma segunda língua, fazem-se necessárias dinâmicas que estimulem a comunicação entre discentes e docentes na sala de aula, pois, segundo Vygotsky (1994), a comunicação é um elemento essencial para o aprendizado da linguagem. Deste modo, é importante que lancemos mãos de ambientes que possam potencializar este aprendizado, como é o caso das tecnologias digitais, que oferecem imensas possibilidades para diminuir as barreiras na aquisição de uma Língua Estrangeira, bem como uma atmosfera colaborativa de ensino-aprendizagem em sala.

Quando pensamos em Tecnologia, normalmente, o que vem a nossa mente são os equipamentos digitais, smartphones, dispositivos com alto nível de sofisticação, como percebemos, uma ideia antiga de tecnologia. Podemos afirmar que todo equipamento que tem como fim a sua utilização como ferramenta para auxílio na realização de alguma atividade, trata-se de tecnologia. Embora os equipamentos que utilizamos em nossas atividades diárias sejam tecnologias, a Tecnologia Digital, por sua vez, corresponde aos equipamentos que funcionam com base em códigos e sistemas complexos, que nos possibilitam realizar diversas atividades como nos comunicar, estudar, jogar e muitas outras que dependem das redes para o seu funcionamento.

Quando utilizadas desta forma, as tecnologias digitais são componentes importantes para o ensino, principalmente o ensino de Língua Inglesa, pois, devido ao caráter universal deste idioma, existe uma grande quantidade de recursos e materiais disponíveis para otimizar o trabalho com o referido idioma, além de serem também oferecidas várias possibilidades de imersão na Língua Inglesa no dia a dia dos discentes, como vídeos, filmes, documentários, jogos e outros recursos.

Para desenvolvimento deste artigo foi realizada uma pesquisa qualitativa de cunho exploratório, cujos dados foram obtidos através da produção final de uma sequência didática, no caso, o jogo digital de nome Kahoot!, que foi aplicado após a observação de 4 
(quatro) aulas em uma turma de quarto ano do curso de Informática Modalidade Integrada, do Instituto Federal da Bahia, juntamente com aplicação de questionário objetivo e realização de entrevista semiestruturada. O questionário objetivo foi aplicado a dez alunos, na referida turma, que se voluntariaram a responder as perguntas que tinham como intenção a coleta de impressões dos discentes sobre o jogo digital aplicado, bem como as dificuldades na sua realização. Também, após a realização do Kahoot!, foram realizadas entrevistas com esses dez discentes, para que eles expusessem seus pontos de vista sobre a atividade realizada e sobre o uso da tecnologia digital nas aulas de Língua Inglesa. Os discentes supracitados estão identificados com o nome Bit ${ }^{1}$, precedido de um número, pois, por questões de ética de pesquisa seus nomes reais foram ocultados.

Este texto está dividido em quatro partes, sendo que a primeira parte contempla a contextualização sobre o ensino de inglês no Brasil, abarcando aspectos históricos e técnicos, além dos parâmetros necessários para que tal ensino ocorra de forma efetiva. Por sua vez, a segunda parte trata de um panorama sobre a tecnologia na sociedade e ainda como os jogos que utilizam tecnologias digitais são dispositivos relevantes para a melhoria das dinâmicas de ensino de Língua Inglesa. A terceira parte aborda a realização do jogo digital em sala de aula, sendo detalhado como ocorreu a dinâmica de aplicação do jogo e as suas reflexões teóricas e práticas, para compreensão do diálogo entre tecnologia digital e ensino de idiomas, do ponto de vista dos estudantes. Na última parte, apresentamos as reflexões gerais sobre esta pesquisa.

\section{O ensino de inglês no Brasil: contextos}

No Brasil, o ensino de Língua Estrangeira foi tornado obrigatório com a vinda de D. João VI, em virtude das relações comerciais que esse mantinha com a Inglaterra, na verdade, não só inglês, mas francês, italiano entre outras línguas europeias eram ministradas em colégios e instituições referenciadas na época (SANTOS, 2018). A promulgação da Lei 
$\mathrm{n}^{\circ}$ 4.024, do dia 20 de dezembro de 1961, sancionada pelo presidente João Goulart, retirou a obrigatoriedade do ensino de inglês nas escolas, porém, em 11 de agosto de 1971, com a promulgação de uma nova Lei de Diretrizes e Bases para a Educação (Lei 5692/1971), a Língua Inglesa retornava paulatinamente à estrutura curricular das escolas, ficando a cargo das instituições a ofertarem, no caso de haver estrutura propícia para isso (Idem).

Somente com a LDB no 9.394, de 1996, sancionada pelo presidente Fernando Henrique Cardoso, foi que o ensino de inglês passou de fato a ser obrigatório a partir do quinto ano do ensino fundamental, além de uma segunda língua, se a estrutura escolar assim permitisse (SANTOS, 2018). Afinal, com todos os avanços pelos quais têm passado a sociedade e a integração entre povos, bem como a rapidez nas comunicações, o ensino de inglês se tornou cada vez mais necessário e relevante para a sociedade de forma geral. Desta forma, O bom domínio de idiomas entra como competência e abordagem necessária no ambiente escolar, reforçando assim a importância de Línguas Estrangeiras na escola, sendo o inglês obrigatório e qualquer outro idioma opcional, desde a aprovação dos Parâmetros Curriculares Nacionais para o Ensino Médio (PCNEM), que dizem:

[...] pensar-se o ensino e a aprendizagem das Línguas Estrangeiras Modernas no Ensino Médio em termos de competências abrangentes e não estáticas, uma vez que uma língua é o veículo de comunicação de um povo por excelência e é através de sua forma de expressar-se que esse povo transmite sua cultura, suas tradições, seus conhecimentos (BRASIL, 2000, p. 30).

Ao prosseguir com estas discussões, é importante perceber no texto acima o trecho: "é através de sua forma de expressar-se que esse povo transmite sua cultura, suas tradições e seus conhecimentos", demonstrando que o ensino de inglês nas escolas precisa acontecer de forma que estimule a interação entre os indivíduos, privilegiando as comunicações e as trocas entre os alunos. Autores como Bakhtin (2003) trazem em seus princípios que um dos pilares fundamentais da aquisição de linguagem é a compreensão de que a língua não é dissociada do indivíduo, mas está vinculada à sua própria existência, sendo somente por meio dela que esse pode transformá-la. 
Esses pressupostos contrariam as tendências ainda vigentes no ensino de Língua Estrangeira, que prezam pelos modelos de tradução ou memorização de vocabulário sem carga crítica ou participação dos sujeitos. O processo de interação no idioma deve promover exercício de fala, escrita, audição e leitura, dessa maneira, sendo inviabilizado com métodos unilaterais de ensino em sala de aula.

Aprender idiomas é um processo que, de acordo com Brun (2003), necessita de interação entre os aprendizes. Assim, o professor, facilitador ou mediador do ensino, necessita conduzir atividades que busquem ao mesmo tempo ensinar e estimular a interação entre os alunos dentro da sala de aula. Também, de acordo com Rocha (2015), um dos maiores desafios no aprendizado do idioma é manter uma prática que permita a aplicação e memorização dos conhecimentos, principalmente se for uma abordagem de ensino linear que é fundamentada somente na entrega de conhecimentos e conteúdos teóricos. Esse contexto, além de dificultar a efetividade do processo de ensino-aprendizagem, desestimula o aluno a buscar conhecimentos por outras vias (Idem).

No entanto, embora tenhamos avançado em termos de recursos para o ensino de Língua Inglesa na escola, ainda enfrentamos barreiras na realização das avaliações. Para compreender a lógica desses métodos de aferir conhecimento, é necessário entender o contexto histórico de como se originaram os panoramas avaliativos em Língua Estrangeira, principalmente, Língua Inglesa, sendo o primeiro paradigma de ensino, o de tradução.

O paradigma gramática-tradução dominou o ensino de línguas da metade do século XIX até a metade do século XX. Neste modelo tradicional, utilizado para aprender línguas clássicas e de prestígio, como o latim e o grego, o objetivo principal é fazer com que o aluno aprenda a traduzir a língua alvo. Apesar de ter tido seu ápice no século XIX, muitas características deste modelo continuam presentes no ensino de línguas (LUCENA, 2004, p. 04).

O método acima tem o objetivo de fazer com que o aluno esteja apto a realizar traduções da língua alvo para a língua materna e vice versa, focando numa determinada "robotização dos conhecimentos", a partir do momento que o aluno tem a língua como um conjunto de regras e vocabulário a serem memorizados. Todavia, esse processo é falho 
de diversas maneiras, a primeira delas é que se torna muito cansativo para o estudante, o desestimulando a continuar a estudar, prejudicando, inclusive, seu aprendizado a longo prazo.

Um dos grandes problemas desse método repousa no fato de que nem todas as habilidades possam ser avaliadas da melhor maneira. Para que haja uma aquisição completa de Língua Estrangeira, é necessário que se pratique quatro habilidades principais, que são: oralidade, leitura, audição e escrita (SANTOS, 2011). Essas habilidades conferem ao estudante o domínio da Língua Estrangeira estudada, permitindo-lhe independência e fluidez em sua comunicação.

O panorama de ensino de Língua Inglesa começou a focar nas habilidades citadas, abandonando os tradicionalismos, adotando uma dinâmica comunicativa especificamente no século XX, pois

a partir da metade do século XX, nos anos 40, o trabalho de linguistas estruturalistas como Bloomfield e Fries influenciou a abordagem estrutural e, baseada nesta abordagem e na psicologia behaviorista, surgiram os modelos de ensino de LE como Áudio-oral e Audiovisual. $\mathrm{Na}$ época, os Estados Unidos se firmavam como uma grande potência e, além do interesse de formar rapidamente seus soldados para falarem as línguas dos aliados e de seus inimigos, havia também o interesse na expansão da Língua Inglesa [...] (LUCENA, 2004, p. 05).

Notamos, diante do exposto acima, que o trabalho de outras habilidades foi incluído aos poucos nos esquemas pedagógicos das escolas ou demais instituições de ensino de Língua Estrangeira como segunda língua. Esta nova configuração é relevante para o ensino de Língua Inglesa, visto que anteriormente havia desprezo total às experiências dos alunos e não-consideração dos seus saberes prévios e, com esse modelo, o conhecimento é entregue num manual que deve ser seguido à risca, o que prejudica a capacidade de comunicação e interação entre os alunos, vital para o bom aprendizado de Língua Inglesa.

Por fim, somente com o aparecimento da psicologia cognitivista que esse cenário começou a se modificar, porque se percebia que o aluno deveria aprender num ambiente favorável e suas experiências deveriam ser respeitadas (LUCENA, 2004). Os processos de aprendizado deveriam ser realizados com criatividade e respeito às dificuldades dos alunos, 
com estas sendo trabalhadas paulatinamente em direção à sua melhoria. Esses ideais foram baseados em autores como Chomsky, que expunha teorias sobre o aprendizado de idiomas e suas relações com a interação entre as pessoas (Idem). Agora, ao invés de aulas e avaliações realizadas somente com estruturas gramaticais e provas repetitivas, existem atividades mais dinâmicas e com maior probabilidade de construir um conhecimento consolidado, o que Portela (2007) chama de Abordagem Comunicativa, o que dinamizou e melhorou o trabalho com o ensino de Língua Inglesa, o tornando mais abrangente e completo no que se refere à escrita, fala, audição e leitura.

\section{A tecnologia digital na sociedade}

As Tecnologias Digitais se configuram como mecanismos que fazem parte da vida das pessoas de maneira direta e indireta, influenciando o modo como nos comunicamos, interagimos com o mundo e, principalmente, produzimos conhecimento. A globalização, bem como a internet, elevou o nível do aprendizado de Língua Inglesa, pois, ao passo que os conteúdos ministrados ficavam contidos na estrutura da sala de aula, com o aparecimento da internet, bem como a ampliação do uso dos computadores, no momento podemos interagir com nativos de outros países e exercitar o aprendizado de línguas (GARCIA, 2009). Há um constante aumento na quantidade de aplicativos digitais disponíveis que possibilitam realização de exercícios, jogos, entre os recursos que facilitam a interação e potencializam o aprendizado $(\mathrm{Idem})$. Convém citar que mesmo os jogos e aplicativos que não foram pensados com fins educacionais, podem ser adaptados ao ensino-aprendizagem.

Esses novos sistemas são trazidos para dentro da sala de aula pelos alunos, tornando-se parte deste espaço, assim, tais recursos se tornam úteis para que o professor os redirecione para sua dinâmica de ensino. Autores como Silva (2002) afirmam que existe uma nova estrutura de sociedade que está organizada em rede e sempre trocando informações. Esse novo contexto social está interagindo de forma interconectada, impactando na maneira com que as pessoas pensam e atuam.

As interações resultam na estruturação e na conformação de novas maneiras de agir e pensar que se modificam ao redor da rede no mundo virtual. Assim, de acordo com Lévy 
(1999, p. 5), o virtual é um ambiente que "usa novos espaços e novas velocidades, sempre problematizando e reinventando o mundo" e "os limites de espaço não são mais dados e há um compartilhamento de tudo, tornando difícil distinguir o que é público do que é privado, o que é próprio do que é comum, o que é subjetivo do que é objetivo”, sem fronteiras. Isso gera o que o autor chama de cibercultura, a qual acontece no ciberespaço que se trata não só do espaço físico, como também de equipamentos, de cabos e de endereçamentos de rede. Portanto, a cibercultura envolve todo o contexto informacional e de comunicação que esses equipamentos suportam.

Com esta realidade, as dinâmicas sociais se transformam e a cibercultura é absorvida à estrutura social humana, expressando uma nova perspectiva da vida em grupos sociais que têm a característica de ser universal, e se conforma como um sistema diferente de todas as organizações de sociedade que tivemos antes (Idem). A cibercultura, então, trata-se da organização cultural contemporânea marcada pelas Tecnologias Digitais, acontecendo no ciberespaço, que por sua vez é definido pela modernidade tecnológica e seu impacto na vida das pessoas (LÉVY, 1999).

É importante citar que a interação não parte somente de Tecnologias Digitais, mas essa última possibilita o acesso a recursos que se tornam relevantes à comunicação, porque além de ser promovida à interação homem-máquina, também se torna possível a interação entre sujeitos.

De acordo com Lévy (2011), os computadores, celulares e aparelhos eletrônicos que se integram em rede não fazem parte de uma realidade per si, mas unificam algo maior que é o espaço virtual, em que há outra concepção de território e linguagem, transformações constantes e modificações rápidas. Ainda de acordo com o autor supracitado, o pensamento se configura como individual, no entanto, o saber é construído coletivamente, desde quando surgiram as primeiras civilizações. Porém, com o ciberespaço as memórias se tornam objetivadas, os pensamentos se tornam tangíveis e com uma capacidade de circulação muito grande, podendo ser compartilhados com um maior número de indivíduos, demonstrando o impacto das Tecnologias Digitais para o aprendizado (LÉEY, 1999). 
A reflexão sobre o papel da informática na educação não pode ser de maneira nenhuma dissociada da função do aluno (ser humano) como constituinte desse contexto. Como já citado, a tecnologia impacta o aprendizado de muitas formas, desde o ambiente doméstico, até o ambiente escolar. Com a informática associada à escola, os alunos podem se tornar protagonistas do seu próprio aprendizado, dado o caráter da informática de produzir a possibilidade da interação aluno-aluno, aluno-professor e aluno-professor-máquina que são condições essenciais para um aprendizado de Língua Inglesa como segunda língua, ou qualquer outro idioma que se almeje aprender.

Por sua vez, abordar jogos digitais na aprendizagem não é possível sem primeiro discutir o papel da ludicidade no ensino e na sociedade. Para iniciar esta discussão, é importante citar que a ludicidade faz parte do próprio comportamento do homem, Luckesi (2000) defende que os seres humanos são lúdicos todo o tempo, não só no ensino, mas nas suas relações sociais, quando aborda o conceito de homosludens, cujo pressuposto é a ludicidade intrínseca na própria natureza humana.

Ensinar/aprender de maneira lúdica significa escapar da natureza tradicional dos modelos conservadores com a presença do professor carrasco e que julga, sala em filas e conteúdos ministrados de maneira cansativa. Para realizar um ensino de forma lúdica, pode-se trazer recursos diferentes para a sala de aula, ou até mesmo, trabalhar sem recursos físico-materiais, desde que seja promovida a interação entre os estudantes. Desse modo, tal ensino deve ser realizado de maneira que o estudante possa enxergar sua realidade e consiga relacionar esse conhecimento a sua vida pessoal. De acordo com Luckesi (2000), as atividades lúdicas são aquelas que proporcionam experiências de plenitude, em que nos envolvemos por inteiro, as quais não se restringem ao jogo e à brincadeira, mas incluem atividades que possibilitam momentos de prazer, entrega e integração dos envolvidos (p. 12).

Vygotsky traz uma concepção sobre o ensino que dialoga com Luckesi à medida que esse preconiza a interação entre os sujeitos para um aprendizado efetivo. Em seus estudos sobre aquisição de linguagens e troca de conhecimento, Vygotsky (1994) defende que, para que haja uma aquisição efetiva da língua, o sujeito deve estar em constante interação, e isso para o ensino de idiomas é muito importante, principalmente quando tais 
interações ocorrem no formato de diálogos, atividades, jogos e modalidades e de acordo com Almeida Filho (1998, p. 19) "deve-se ter sentido aprender uma Língua Estrangeira, a qual venha proporcionar a interação com o outro, numa busca de experiências profundas e válidas".

Os jogos, hoje em dia, por conta de seu dinamismo, facilidade e acessibilidade têm se tornado ferramentas relevantes para o maior dinamismo na sala de aula. De acordo com Aristóteles o jogo é uma atividade que tem fim em si mesma, algo intrínseco à natureza humana, mas que pode ser utilizado como ferramenta aliada à prática pedagógica. Como afirma Luckesi (2004), quando o ser humano está em contato com uma aprendizagem lúdica, ele pode se comprometer melhor com o processo, vivendo uma experiência plena e imersiva no aprendizado.

É importante ressaltar o caráter formativo através da interação, presente nos jogos digitais, visto que esses têm a característica de retornar aos estudantes um feedback imediato das respostas e dos resultados obtidos, tendo um papel importante sobre o ganho de conhecimento do sujeito e auxiliando seu processo de formação na escola (LEVAY, 2015). Por conseguinte, os jogos digitais, geralmente, progridem de nível, aperfeiçoando seus níveis de dificuldade, ensinando os jogadores a ultrapassarem seus limites e aumentarem seus níveis de proficiência em determinado conteúdo, por exemplo, conteúdos gramaticais em Língua Inglesa(idem).

A diferença entre os jogos tradicionais e os que se utilizam de tecnologia digital reside no fato de que os primeiros apresentavam normas e regras pré-estabelecidas e já se configuravam muito produtivos para interação e aprendizagem, ao passo que nos jogos digitais há uma construção maleável e contínua, permitindo ao sujeito trilhar um caminho mais independente (SILVA, 2016). No entanto, os jogos eletrônicos trazem melhores perspectivas à medida que criam ambientes, detalhes minuciosos e maiores possibilidades de imersão na atmosfera do conteúdo ensinado, a depender do objetivo do professor. Jogos que utilizam quizzes de perguntas e respostas, com plataformas em computadores e/ou celulares podem mobilizar diferentes conhecimentos, bem como promover aprendizado, visto que se pode ter acesso às respostas a posteriori, no momento em que se joga (Idem). 
Por conseguinte, os estudantes podem se interessar pelos conteúdos de melhor maneira e se tornarem protagonistas de seu aprendizado.

\section{A informática no ensino de Língua Inglesa: o Kahoot! como possibilidade pedagógica}

Segundo Zabala (1998, p. 18), a Sequência Didática se trata de "um conjunto de atividades ordenadas, estruturadas e articuladas para a realização de certos objetivos educacionais, que têm um princípio e um fim conhecidos tanto pelos professores como pelos alunos[...]" (p. 18). No entanto, como temos por objetivo demonstrar os impactos da tecnologia digital no ensino de Língua Inglesa, focaremos apenas na produção final da Sequência Didática, que se trata do jogo digital Kahoot!. Tal jogo foi escolhido por possuir uma plataforma rica em possibilidades de elaboração de perguntas, interação entre jogadores de forma individual e em grupo, permitindo inserção de gravuras, vídeos, possibilitando aos professores a articulação de diversas habilidades ao mesmo tempo.

A aplicação do jogo digital aqui proposto é um procedimento importante, que demonstra como a tecnologia tem potencial importante que pode ser utilizado para investir num bom ensino-aprendizagem na sala de aula. Os jogos digitais são capazes de promover interação entre os sujeitos na sala de aula, além de oportunizar um ensino lúdico, que entre suas inúmeras vantagens, podem ser destacadas as possibilidades de o professor perceber o desempenho da turma, bem como seu nível de conhecimento sobre determinado assunto.

O jogo Kahoot!, que foi utilizado na nossa intervenção, pode ser encontrado no Website www.kahoot.com ${ }^{2}$ e se trata de um aplicativo que promove competições que podem acontecer entre um determinado grupo de estudantes, ou de forma individual, e jogam contra a própria interface do aplicativo, conforme se observa na Figura 01: 
Figura 01 - Interface do aplicativo Kaboot

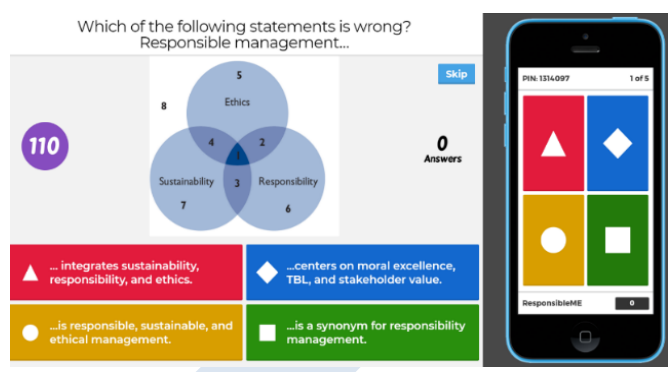

Fonte: Responsible management ${ }^{3}$

A figura 01 exibe a interface da plataforma Kahoot!,onde o destaque em vermelho indica a forma como os jogadores enxergam as perguntas e, por sua vez, o destaque em azul demonstra como os estudantes veem as opções para escolha das respostas corretas.

Aplicamos o jogo digital citado na turma de $4^{\circ}$ ano do IFBA, com participação de toda a classe (26 alunos), porém, somente entrevistamos dez estudantes que se voluntariaram para responder as perguntas sobre a atividade. O conteúdo abordado no jogo foi baseado no assunto Reported Speech, que se trata de um conteúdo gramatical da Língua Inglesa. Destarte, na plataforma utilizada para realização do jogo, foram realizadas perguntas baseadas em tal conteúdo por meio de um questionário virtual com os discentes, para avaliar o aprendizado alcançado até aquele momento, visto que houveram aulas expositivas sobre o Reported Speech anteriormente.

\section{Da aplicação}

Para aplicação da sequência didática foi solicitado aos discentes que se dividissem em quatro grupos, da maneira que desejassem, e utilizassem somente um smartphone por grupo, com a sala sendo da seguinte forma organizada 4 :

${ }^{3}$ Disponível em http://responsiblemanagement.net/kahoot-quizzes-textbook-principles-of-responsible-management/. Acesso em janeiro de 2020

${ }^{4}$ Por questões éticas, ocultamos o rosto dos alunos com os emojis. 
Figura 02 — Organização da turma para a realização do Jogo Kahoot!

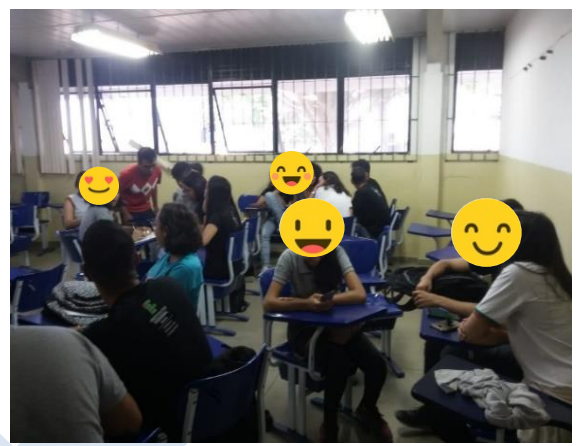

Fonte: Elaboração própria.

Durante a aplicação da atividade, alguns discentes tiveram dificuldades pontuais, em virtude da diversidade de aparelhos e de interfaces para operacionalização da atividade proposta, mas nada que atrapalhasse o seu desempenho, pois de maneira muito rápida as dúvidas foram sanadas e o trabalho prosseguiu. Observamos nos estudantes muita euforia e animação por estarem realizando uma atividade diferente, utilizando completamente interfaces tecnológicas. Os discentes foram reunidos em grupos por serem muitos, visto que individualmente eles não conseguiriam interagir para alcançar os resultados esperados.

Segundo Vygotsky (1994), bons resultados na aprendizagem se caracterizam pela interação, seja entre professor-aluno ou aluno-aluno, foco da nossa Sequência Didática. Assim, pudemos observar que os discentes estavam se questionando a todo momento sobre quais seriam as respostas corretas, visto que havia somente um smartphone em cada grupo de estudantes. Dessa maneira, eles poderiam interagir da melhor maneira possível. A Figura 03, a seguir, demonstra a organização dos discentes em quatro grupos, bem como os nomes das equipes por eles escolhidos, quais sejam: 


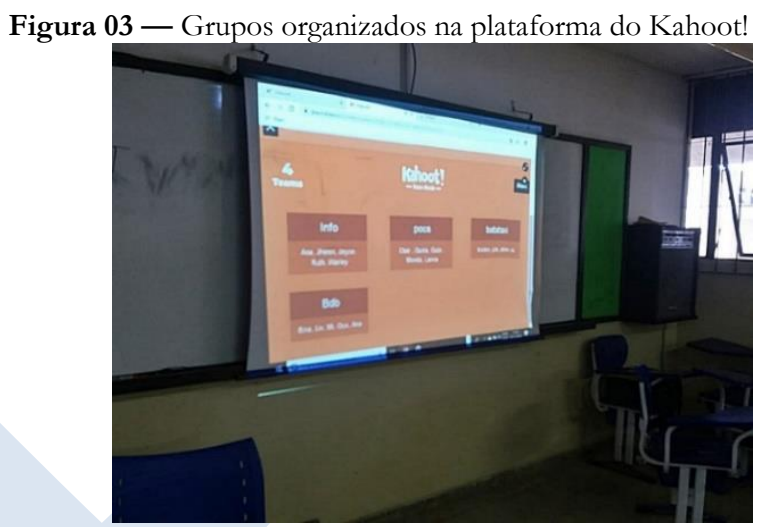

Fonte: Elaboração própria.

De acordo com Vygotsky (1994), o ser humano consegue agir, interagir, comunicarse e existir no ambiente por intermédio de outro ser, mostrando-se como sujeito não-passivo no ambiente, dessa forma, produzindo o próprio conhecimento. Do mesmo modo, de acordo com Perrenoud (1998), mediante trocas dentro da sala, entre estudante e professores, é possível construir bases relevantes para os alunos, a fim de que esses possam auxiliar mutuamente em sua construção de conhecimento e avaliação. Por isso, vimos a importância de realizar essa atividade em grupo, para que os alunos pudessem construir seu conhecimento de forma conjunta, e também, em grupo, pudessem definir um nome e gerar identidade e aproximação entre si, facilitando os trabalhos e criando um clima agradável coletivamente.

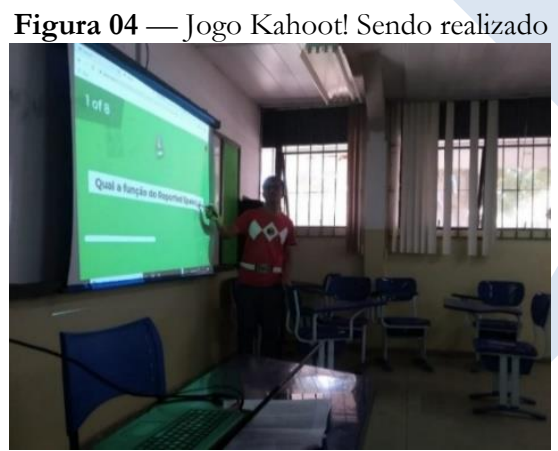

Fonte: Elaboração própria. 
A Figura 04 representa a atividade em curso e mostra que até esse momento os alunos apresentavam bom desempenho, observadas as respostas apresentadas, bem como o trabalho cooperativo que estava sendo realizado conforme observado na Figura 05.

Figura 05 - Grupos Engajados durante o jogo Kahoot!

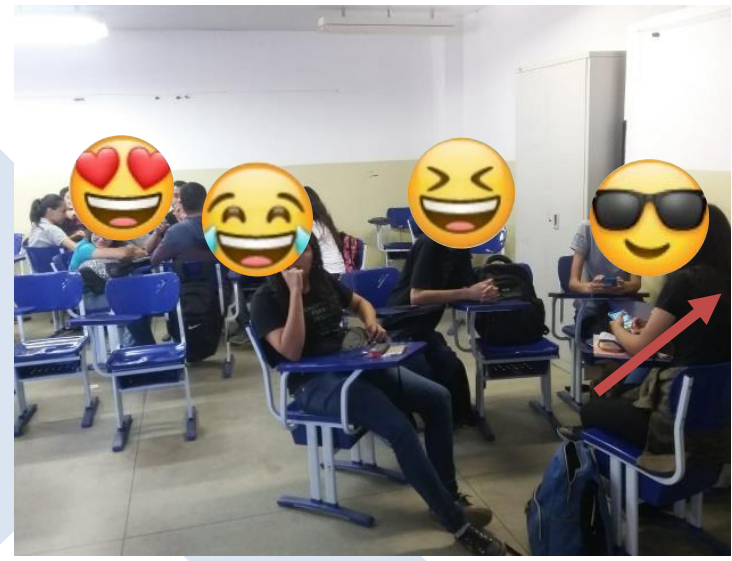

Fonte: Elaboração própria.

A seta laranja destaca a aluna segurando o smartphone, quando um dos colegas a ajudava com a seleção da resposta correta, enquanto dois discentes estavam conferindo, novamente, os objetivos das questões.Estas ações nos permitem perceber um trabalho de cooperação entre os discentes, e, posteriormente, foi exibida a classificação final dos grupos (Figura 06).

Figura 06 - Classificação final dos grupos

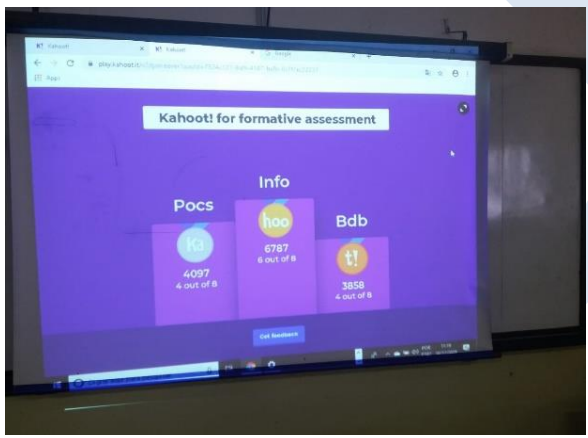

Fonte: Elaboração própria. 
A Figura 06 representa o término do jogo e exibe a classificação das equipes, ao fim da atividade. Durante o jogo digital as respostas corretas eram exibidas a posteriori, da mesma maneira, algumas perguntas foram reformuladas, com o mesmo conteúdo de questões anteriores, mas com outra estrutura para certificação de que os alunos conseguiriam entender a lógica do exercício e do conteúdo. Entretanto, os resultados não foram tão destoantes entre os grupos, mostrando certa sintonia da turma em termos de conhecimento.

Ao finalizar a atividade, realizamos um questionário com os discentes para colher suas impressões a respeito de possíveis facilidades e/ou dificuldades em sua realização e para atestar se metodologias como esta são viáveis para serem realizadas como potencial avaliativo. A primeira pergunta tratou das dificuldades durante a realização das perguntas no jogo Kahoot!, cujo resultado demonstrou que nove, dos dez alunos que responderam aos questionários, afirmaram que não tiveram dificuldades com a atividade realizada; e o único estudante que apontou dificuldades, explicou-nos que houve um problema de incompatibilidade momentânea no aparelho, que foi logo resolvida.

Essa informação é relevante pois demonstra que os alunos são capazes de operacionalizar os exercícios que envolvem tecnologias digitais dentro da sala de aula, o que corrobora com Prensky (2001), segundo o qual os alunos hoje em dia manipulam com muita facilidade tecnologias digitais por já manterem contato desde pequenos com estas tecnologias. Por isso, pensar sua inserção dentro da sala de aula é possível e relevante para planejar novas formas de promover inovação nos currículos escolares.

Outra questão abordou se os alunos se sentiriam mais motivados para estudar com o uso de tecnologias digitais. Sobre esta questão todos responderam positivamente, o que nos remete ao que salienta Silva (2016), para quem a vantagem das tecnologias digitais reside em colocar o aluno como sujeito ativo dentro da sala de aula, ou seja, como autor da sua própria construção de conhecimento. As dinâmicas produzidas pela tecnologia estimulam o aluno por mantê-lo entretido, ao passo que promove a interação constante. Quando bem utilizada em termos pedagógicos, promove ludicidade por intermédio do meio digital. 
Segundo Luckesi (2004), a ludicidade motiva o aprendizado e expande o aprender para além da tecnicidade, da produção de mensagens e de estímulos, da bidirecionalidade da informação e de outros conceitos sobre tecnologia abordados pelos autores que a estudam. Ao levar a tecnologia digital para a sala de aula estamos levando parte integrante do dia a dia dos discentes para o ambiente escolar.

\section{Reflexões da tecnologia como aliada ao ensino de Língua Inglesa}

O ensino de Língua Inglesa demanda a criação de um ambiente colaborativo, em que seja possível a interação entre os sujeitos da sala de aula, neste caso, docentes e discentes, de modo que através da comunicação sejam capazes de exercitar as habilidades necessárias para o aprendizado. Jogos Digitais em formato de quizzes virtuais como o Kaboot! podem oferecer uma plataforma importante para tal exercício, visto que oferecem liberdade na criação de questionários, podendo-se assim adaptar questões que exercitem oralidade, audição, e também, ao ler as questões projetadas, os discentes estão exercitando a habilidade de leitura.

A tecnologia oferece a possibilidade de dinamizar os conteúdos em sala, bem como abrir uma gama infinita de possibilidades que podem aprofundar a convivência dos alunos com o mundo externo, trazendo uma grande possibilidade de vivências dos alunos e modificando a atmosfera tradicional presentes numa aula expositiva. De acordo com o aluno Bit 01, quando indagado sobre o porquê de atividades como a realizada serem importantes para o ensino-aprendizagem, ele respondeu:

Bem interessante também essa atividade, porque não fica como aquele tipo de atividade teórica em que o aluno só tem que escrever. Então, a brincadeira ajuda a entender o assunto de uma forma mais prática (BIT 01) (Trecho de entrevista realizada no dia 05/03/2020 aluno - BIT 01)

Assim, notamos que o aluno cita que atividades como esta ajudam na compreensão de conteúdos escolares, uma vez que acontecem de maneira diferente, tornando os conteúdos mais fáceis para compreensão. Além disso, o ensino de idiomas de maneira geral, 
segundo Oliveira e Paiva (2001, quando ocorre de maneira tradicional, pelos paradigmas de tradução, por exemplo, desestimula e retira o interesse por seu estudo, o que se torna danoso, visto que o conhecimento de inglês é fundamental para a vida profissional no presente século XXI.

Para entender qual seria o papel da tecnologia digital nas escolas como possibilidade pedagógica, é necessário compreender sua importância como instrumento no auxílio da conversão de estudantes de meros indivíduos passivos na sala, em agentes capazes de interagirem na construção de conhecimento, pois a tecnologia lhes confere a capacidade de

ouvir, ver, ler, gravar, voltar, ir adiante, selecionar, tratar e enviar qualquer tipo de mensagem para qualquer lugar. Em suma, a interatividade permite ultrapassar a condição de espectador passivo para a condição de sujeito operativo (SILVA, 2016, p. 06).

Diante dessa perspectiva, pensamos no Kahoot! como plataforma para explorar o tema da tecnologia, porque essa plataforma é propícia para a realização de atividades de ensino-aprendizagem e, por se tratar de um jogo digital, o Kahoot! exercita habilidades de conhecimento, habilidades sociais, bem como ajuda na memorização e concentração como, em geral, propõem-se os jogos digitais com fins pedagógicos (LEVAY, 2015).

Além de possuir uma parte dedicada a avaliações, a plataforma citada insere o aluno como sujeito ativo na sala de aula, além de criar um ambiente de interação tanto entre estudante-professor, quanto estudante-estudante e estudante-máquina. Essa atmosfera de interatividade entre os constituintes da sala de aula se torna lúdica e produtiva, porque as comunicações acontecem em tempo real, o que para a dinâmica em sala se torna importante, como cita o estudante Bit 03:

Eu acho que para todo mundo foi algo novo. Acontecem algumas atividades relacionadas a informática, mas não tão [...] tipo a gente vê ali em tempo real, um negócio mais diferente (Trecho de entrevista realizada no dia 05/03/2020 - estudante Bit 03)

Observamos que um dos pontos citados pelo estudante Bit 03 "a gente vê ali, em tempo real", demonstrando que a característica de retorno das informações e da interatividade se mostrou positiva para o aprendizado dos alunos, de modo que esses afirmaram 
fixar melhor alguns conteúdos de gramática. Quando indagada se atividades que se utilizam de tecnologia digitais e promovem interação podem ser usadas como uma alternativa para melhorar o aprendizado, a aluna Bit 04 respondeu: “Acho que sim, porque eu estudei só um pouco e logo quando fazia as perguntas eu conseguia responder rápido, então, deu pra fixar".

Assim, conforme assevera Lévy (1999), o ciberespaço que integra a sociedade é um espaço heterogêneo, onde há interatividade e intercomunicação, de modo que não podemos ignorar sua potencialidade de melhorar as relações dos alunos com aspectos que envolvem o ensino-aprendizagem, e também por sua possibilidade de exercício de idiomas tendo em vista a imersão mundial no idioma inglês. As atividades que utilizam tecnologia digital para aprendizado se constituem como ferramentas relevantes pois

podem apresentar ciclos de aprendizagem em que o jogador erra, consequentemente tem que refletir sobre o erro e identificar a causa $[\ldots]$ o aluno/jogador formula a hipótese em cima da causa do erro, toma atitudes para tentar solucionar o problema, e então, testa e analisa a hipótese $[\ldots]$ agindo ativamente no processo (LEVAY, 2015, p. 44).

Desta forma, sobre o tema da atividade realizada - o Reported Speech -, puderam ser realizadas questões sobre a organização sintática das frases, pois, o referido tema é avançado, contendo peculiaridades que necessitavam ser exercitadas, que poderiam ser maçantes com aulas meramente expositivas, porém, através de jogos digitais, foi possível que os alunos exercitassem e tivessem a todo momento retorno de seus resultados. Pudemos atestar tal fato quando a aluna Bit 05 questionada sobre a atividade realizada para o ensino de Língua Inglesa respondeu: "Eu achei muito interessante, uma maneira lúdica de aprender as mesmas coisas que a gente aprende normalmente com o livro didático. Eu achei bem divertido" (Trecho de entrevista realizada no dia 05/03/2020 - aluna Bit 05).

Pudemos perceber a importância do caráter lúdico da tecnologia, que mostrou aceitação dos alunos em relação à atividade realizada de modo que, para além dos pressupostos teóricos sobre a utilização positiva da tecnologia em sala, pudemos perceber a importância da tecnologia e ludicidade no ensino de Língua Inglesa quando o aluno Bit 10 respondeu: 
"Ah eu acho que quem tem pode sim usar celular, porque faz parte da vida de todo mundo, né? Se tiver como usar de um jeito bom, porque não?”. Segundo Howard e Mozejko (2015) existem diversas barreiras à utilização dos aparatos tecnológicos, e dentre estas barreiras temos a própria resistência das instituições que muitas vezes não inserem a utilização dos equipamentos em seus planejamentos, em virtude da falta de confiabilidade em seu funcionamento no dia das atividades, pois para o trabalho com tecnologia são necessários diversos recursos humanos e não-humanos que nem sempre estão disponíveis nos dias das aulas.

Segundo Levay (2015), uma das maiores dificuldades que temos na adoção de práticas que utilizam tecnologia digital na escola é o fato de a internet ser muito vasta em conteúdo, e encontrar aplicativos ou websites que contenham atividades com conteúdos focados no assunto trabalhado é uma tarefa difícil. Neste ponto, uma das vantagens na utilização do Kahoot! foi a possível adaptação do conteúdo previsto em atividades dinâmicas, porque a elaboração do questionário é livre, desta forma vemos a necessidade de formar os professores para que conheçam as tecnologias digitais e saibam onde encontrá-las. Segundo Nóvoa (1998), é importante que seja possibilitado aos professores a realização de trabalho colaborativo para que as experiências sejam compartilhadas, pois, através do compartilhamento de práticas entre os docentes, é possível que o trabalho tecnológico seja estendido ao corpo escolar como um todo, e não ficar restrito a somente um docente na escola, o que ajuda a superar a resistência do corpo pedagógico escolar.

Como percebido, existe diversas possibilidades para a utilização da tecnologia de forma aliada ao ensino de Língua Inglesa, porém, é importante que sejam utilizadas as plataformas corretas para cumprir tal objetivo, como é o caso da plataforma Kahoot!, aplicada na sequência didática, que, dependendo de sua organização, mobiliza de forma direta e indireta as quatro habilidades para o aprendizado de Língua Inglesa, de acordo os docentes estruturam as questões e as alternativas na plataforma.

Se trabalhamos com a perspectiva da avaliação da habilidade "escrita", ambientes como editores de textos, inclusive o próprio celular pode fornecer correções dos vocabulários solicitados, ou então, os textos produzidos podem ser publicados em grupos de redes sociais, em que todos os colegas podem ter acesso. Afinal, de acordo com Santos (2012), 
em sala de aula a participação de todas as pessoas não é assegurada, no entanto, ao publicar no virtual, todos os que têm acesso ao ciberespaço podem verificar o que foi escrito e fornecer feedback e correções.

Partindo da premissa de trabalhar a "leitura", os alunos têm a possibilidade de serem redirecionados a leituras de sites, notícias, exercícios de vocabulários e jogos que têm conexão com Língua Inglesa, geralmente disponíveis na internet, e programas como o Kahoot! podem intermediar perguntas e respostas com o objetivo de promover avaliação daquela habilidade. Dado seu caráter instantâneo de reposta, a internet pode ser uma boa aliada à prática docente no ensino de idiomas, não só da Língua Inglesa como segunda língua, mas em disciplinas como Língua Portuguesa, entre outras que trabalham interpretação de texto e de informações.

Exercitando a audição existe a possibilidade de utilizar vídeos, filmes e músicas, pois existem plataformas que desenvolvem atividades para trabalho com músicas. Desta maneira, além de ser criado um ambiente mais lúdico para a sala de aula os alunos conseguem treinar audição e escrita, principalmente se forem atividades de preenchimento de espaços em branco com as palavras faltantes, que são atividades muito comuns em cursos de Língua Inglesa como segunda língua. Podemos citar como exemplo a plataforma Lyrics Training ${ }^{5}$.

E, por fim, se estamos tratando da competência da "fala", existe a possibilidade de utilização de plataformas de conferência que promovem o contato de pessoas do mundo entre si, além de plataformas gratuitas que registram gravações e devolvem feedback com o que foi dito, ou se o que foi dito obedece ao que é solicitado pelo aplicativo ou programa, a exemplo do Duolingo ${ }^{6}$, que é um aplicativo de aprendizado de Língua Inglesa.

Portanto, notamos que é importante investir em formas de possibilitar o acesso a ambientes e exercícios adequados, bem como fornecer indicativos de como trabalhar determinados recursos. Também, é importante que as escolas invistam na estrutura e no

5 Disponível em: https://yricstraining.com/app?nr $=1 \& \sim$ channel $=$ web $\& \sim$ feature $=$ redirect $\& \sim$ campaign $=$ none\&ref $=$ https $\% 3 \mathrm{~A} \% 2 \mathrm{~F} \% 2$ Flyricstraining.com $\% 2 \mathrm{~F}$

${ }^{6}$ Disponível em centros de aplicativos para diferentes plataformas de celular. 
funcionamento de seus aparatos tecnológicos, para que não haja desconfiança dos profissionais e dos discentes quanto à utilização de tecnologias digitais na classe como possibilidade pedagógica. Dessa forma, poderá haver clareza dos objetivos da tecnologia no ensino, de modo que haja superação dos desafios e das resistências que cercam a utilização da Tecnologia Digital. Torcemos para que a tecnologia possa ser utilizada sobretudo no ensino de Língua Inglesa, visto que os idiomas e a cultura estão em constante atualização e a tecnologia digital pode possibilitar o acompanhamento dessas transformações, bem como trazê-la para a sala de aula.

\section{Considerações finais}

Percebemos que a ludicidade é uma ferramenta importante para que o ensino de inglês aconteça, pois, este ensino não pode estar resumido somente a traduções e aquisições de vocabulários aleatórios, mas, deve, principalmente, estar conectado a uma prática que envolva o exercício da audição, da fala, da escrita e da leitura. A tecnologia digital é uma boa alternativa para o trabalho com a Língua Inglesa, visto que se utilizada de forma correta pode auxiliar no desenvolvimento de atividades que estimulem a interação entre os sujeitos, bem como trabalhe as habilidades necessárias para o aprendizado de Língua Inglesa.

Os resultados da nossa pesquisa evidenciaram que os discentes demonstraram se interessar pelo uso de tecnologias digitais dentro da sala de aula, a exemplo do uso de dinâmicas como a atividade realizada, desta forma, se a sociedade gira ao redor da ideia de digital, é importante que o ensino-aprendizagem acompanhe esta dinâmica, tanto com o objetivo de melhorar o aprendizado, quanto para aumentar o interesse dos alunos pela escola. Desta forma, é importante que haja investimentos na educação para a realização do trabalho pedagógico com auxílio da tecnologia, com a garantia de equipamentos e segurança para um planejamento que tenha eficácia, assim como é relevante que os docentes tenham uma atmosfera colaborativa que possam compartilhar conhecimentos e experiências, sabendo onde encontrar e como utilizar ferramentas que sejam úteis para promoção de um ensino de Língua Inglesa lúdico e eficaz, contemplando as habilidades necessárias para seu aprendizado. 


\title{
DIGITAL TECHNOLOGY IN ENGLISH LANGUAGE TEACHING: THE KAHOOT! AS FORMATIVE EVALUATION
}

\begin{abstract}
The present work is the result of a research cut resulting from a master's dissertation, whose research was carried out in a fourth-year class of High School, from the Informatic course in the Integrated Modality (professional degree with High School) at the Federal Institute of Bahia, campus Vitória da Conquista. The general objective of this article was to investigate how Formative Assessment, mediated by Digital Technologies, can enhance the teaching-learning process of English. Although several aspects have been addressed in this dissertation, we focus on digital technology and its potential as an important tool for conducting teaching and learning the English language in a playful and efficient way. Based on authors such as Lucena (2004), Brun (2003) and Levy (1999), we carried out a qualitative research of an exploratory nature, whose data collection focused on the collection of results through the application of the digital game Kahoot! (final production of a didactic sequence). We realize that digital technology has the ability to contribute to teaching English in a dynamic way, in addition to promoting a playful environment in the classroom, which arouses students' interest in such activities, since society is constantly evolving in increasingly digital world.
\end{abstract}

KEYWORDS: Teaching English Language; Digital Technology; Formative Evaluation.

\section{REFERÊNCIAS}

BAKHTIN, Mikhail. Estética da criação verbal. 4. ed. São Paulo: Martins Fontes, 2003.

BRUN, Milenna. Dificuldades na aprendizagem de línguas e meios de intervenção. 2003. Disponível em: <http://www2.uefs.br/sitientibus/pdf/29/dificuldades_na_aprendizagem_de_linguas.pdf $>$. Acesso em: 31 de março de 2018.

GARCIA, Paulo Sérgio. A Internet como nova mídia na educação. 2009. Disponível em: http://www.educadores.diaadia.pr.gov.br/arquivos/File/2010/artigos_teses/EAD/NOVAMIDIA.PDF. Acesso em: 13 dez. 2019.

HOWARD, S. K., Chan, A., Mozejko, A. \&Caputi, P. Technology practices: Confirmatory factor analysis and exploration of teachers' technology integration in subject areas, Computers \& Education, 90(1): 24-35. 2015.

KIYA, Marcia Cristina da Silveira; DIONIZIO, Fátima Aparecida Queiroz. O uso de Jogos e de atividades lúdicas como recurso pedagógico facilitador da aprendizagem. 2014. Disponível em: http://www.diaadiaeducacao.pr.gov.br/portals/cadernospde/pdebusca/producoes_pde/2014/2014_uepg_ped_pdp_marcia_cristina_da_silveira_kiya.pdf. Acesso em: 09 dez. 2019.

LEVAY, Paula Bastos. Jogos digitais no ensino e aprendizagem de inglês para crianças. 2015. $128 \mathrm{f}$. Dissertação (Programa de Pós-Graduação em Tecnologia e Gestão em Educação a Distância) - Universidade Federal Rural de Pernambuco, Recife. 
LUCENA, Maria InêzProbst. Avaliação no ensino de línguas e contemporaneidade: em busca de uma re-significação. 2004. Disponível em: http://www.leffa.pro.br/tela4/Textos/Textos/Anais/CBLA_VII/pdf/051_lucena.pdf. Acesso em: 14 dez. 2019.

LUCKESI, Cipriano Carlos. Educação, ludicidade e prevenção das neuroses futuras: uma proposta pedagógica a partir da Biossíntese. In: LUCKESI, Cipriano Carlos (org.) Ludopedagogia

— Ensaios 1: Educação e Ludicidade. Salvador: Gepel, 2000.

NÓVOA, A. Os professores e a sua formação. Lisboa: D. Quixote, 1992.

PAIVA, Vera Lúcia Menezes de Oliveira e. A www e o ensino de inglês. Rev. bras. linguist. apl., Belo Horizonte, v. 1, n. 1, p. 93-116, 2001. Available from < http://www.scielo.br/scielo.php?script $=$ sci_arttext\&pid $=$ S1984-63982001000100006\&lng=en\&nrm =iso $>$. access on 25 Oct. 2020. https://doi.org/10.1590/S1984-63982001000100006.

PERRENOUD, Phillipe. Avaliação: da excelência à regularização das aprendizagens: entre duas lógicas. Porto Alegre, Artmed, 1998.

PRENSKY, M. Digital Native, digital immmigrants. Digital Nativeimmigrants. Onthehorizon, MCB University Press, Vol. 9, N.5, October, 2001. Disponível em: https://www. marcprensky.com/writing/Prensky\%20-\%20Digital\%20Natives, \%20Digital\%20Immigrants\%20-\%20Part1.pdf. Acesso em: 07 de dezembro de 2019.

SANTOS, Edméa Oliveira dos. Formação de professores e cibercultura: novas práticas curriculares na educação presencial e a distância. Revista da Faeeba: Educação e Contemporaneidade, Salvador, v. 11, n. 17, p.113-122, jun. 2012. Semestral.

SANTOS, Eliana Santos de Souza e. O ensino da Língua Inglesa no Brasil. Babel: Revista Eletrônica de Linguas e Literaturas Estrangeiras, Alagoinhas, v. 1, n. 1, p.1-7, 21 out. 2018.

SILVA, Jean Cario da. Produção de jogos digitais por jovens: uma possibilidade de interação com a Matemática. 2016. 227 f. Tese (Doutorado em Educação) - Universidade Federal de Uberlândia, Uberlândia, 2016.

SILVA, Marco. Sala de Aula Interativa. Rio de Janeiro: Quartet, 3ª ed. 2002. 220 p.

VYGOTSKY, L. S. A formação social da mente. São Paulo: Martins Fontes, 1994.

ZABALA, Antoni. A prática educativa: como ensinar. Porto Alegre: Artmed, 1998.

Recebido em: 15/11/2020.

Aprovado em: 30/12/2020. 